\title{
Regional-urban evolution of the metropolitan area of Mexicali 1990-2010: planning changes and challenges
}

\author{
A. Ranfla-González ${ }^{1}$, C. Pena-Salmon ${ }^{2}$, \\ R. Rojas-Caldelas ${ }^{2}$, O. Leyva-Camacho ${ }^{2}$, \\ E. Corona-Zambrano ${ }^{2} \&$ C. R. García Flores ${ }^{1}$ \\ ${ }^{1}$ Social Sciences Research Institute, \\ University Autonomous of Baja California, Mexico \\ ${ }^{2}$ Faculty of Architecture, \\ University Autonomous of Baja California, Mexico
}

\begin{abstract}
The regional-urban development planning is a relatively recent response to the changes in the economic processes of production and foreign trade which experienced profound changes over the past two decades. With these changes, globalization and national openness impacted the economic, social and territorial relations in the metropolitan area of Mexicali. This area experienced a central expansion increasing the mobility of vehicles. The importance of urban-regional network in its territory also augmented. These changes impacted the economic base, gradually reducing the importance of agriculture and industry while services, mobility and economic diversification in the territory of Mexicali increased. The desert environment, demographic concentration and mobility in a very small territory with a very dry and warm weather, have posed challenges for future sustainable development in its metropolitan territory. From the results and the experience of a collective planning process and of civic integration, key challenges were identified in the scenarios to promote appropriate and successful answers in the planning of sustainable development for an extreme territory and with economical competence.
\end{abstract}

Keywords: regional-urban planning, metropolitan areas, territorial planning, sustainable planning development. 


\section{Introduction}

Urban development resulted in global relations and urban linkages providing important clues about the social, economic and political dynamics that shaped the texture of human life in much of the world today, both in developed and developing countries alike [1]. Important changes in the size and definition of urban areas impact the current urban planning, because of the modification of their local and global scales. This is leading development to key changes in local relationships that modify the scale and structure of geographical units, as well as impacting environmentally the local insertion in global networks and responding for the evolution achieved by their local organizations in competitiveness and quality of life (Castells and Cardoso [2]).

The transformations in the global economy led to significant changes in the process of urban expansion in the demographic, economic, social and environmental variables in the metropolitan areas of developed and developing countries in recent decades. In Mexico, the territorial transformations were reflected in policies, programs and projects at the metropolitan level, in order to respond to changes in each of them and to the challenges of the study period. This resulted that in 2010, 59 Metropolitan Areas in Mexico concentrated 56.83\% of the total population [3]. In response to these changes, the Ministry of Agrarian, Land and Urban Development (SEDATU) was created in 2013, which legally integrated the rural-urban populations of the largest urban areas of the country and marked important changes in urban planning [4].

In the Metropolitan Area of Mexicali, BC, the economic, demographic and social variations that impulsed its original border location into the first decade of the XXI century were added together, in its passage from a desert into an urban concentration with an economic competitiveness developed by its global integration that turned it into a major metropolitan area important at a national level [5]. In this framework, its urban development has the key characteristics of the extreme weather on its territory [6], aside from having a high vehicular mobility at the level of the largest metropolitan areas of Mexico [7]. This combination of factors has an impact on economic, demographic, regional and social changes, and pose challenges to its sustainable urban-regional planning. The purpose of this paper is to identify and establish key challenges in its future development and urbanization, starting from active economic conditions and the natural environment of its territory in the evolution of its changes.

\section{Methodology}

The conceptual basis of territorial analysis is based on the concept of City-Region, as the territorial space in which geographical, cultural and administrative factors are concentrated, with political conscience and strength in which groups intervene who believe and fight for development through processes of growth and change that lead to improved welfare and sustainability for future generations, in a society that needs to use and optimally manage its natural, economic, cultural and social resources [8]. They are aspects that contribute to build a better quality of life based 
on the promotion of freedom, human dignity, and greater personal opportunity, that make possible a collective satisfaction that promotes environmental compatibility, that respect ecosystems, and increased productivity for future generations.

From the use of documentary evidence and its geographical distribution, we sustain the levels of territorial analysis we use. The information is related quantitatively and qualitatively at a territorial level for its analysis, for which we link its levels of information and subsequent aggregation to respond to territorial analysis. In order to contrast the information with various sources and areas of development, we use a database of essential information to define a metropolitan vision with a long-term perspective. From this information of the Metropolitan Area of Mexicali, under a hierarchical arrangement of sectors of the population, economic activity, and other sectors that register human impact on the regional environment, we use the scale (population size), intensity (level of economic activity) and impact on the environment, to obtain regional-urban scenarios of the Metropolitan Area of study and to identify key challenges in the promotion of its future development.

For this purpose, the methodological basis was based on the experience of participation in the Mexicali Grand Vision 2011-2050 Project [9], which was constituted by the intense participation of the private and social sector in an effort to define the metropolitan vision with a long-term perspective. This proposal had a specific methodology that included: a) an interlocutor group that formed the basis of shared decision between the public, private and social sectors; b) a group of honorary experts invited in the issues under discussion, who supported the formulation of the logical framework and identified strategic actions, that give foundation to the detailed proposal of development vision, from specialized studies in urban, economic and social development. From this, the key issues were defined to identify the challenges for the future development of the Metropolitan Area studied.

\section{Results}

\subsection{Characteristics of population distribution in the metropolitan territory, climate and mobility}

After the 1980s, urban processes experienced significant changes in their spatial distribution, which changed cities worldwide. Changes in development carried differentiations in urban activities, widened metropolitan areas and marked historical changes in the scale and scope of its regional levels. This had an impact on population distribution and economic activities that territorially impacted government plans, production networks and regional spaces of consumption. In the case of Mexicali, these changes posed a major problem resulting from its internal conditions and external changes that also increased in the first decade of the XXI century [10], which it impulsed internally: to have a reduction of the metropolitan territory and to visualize the geographical distribution of human 
settlements, to evaluate, design and plan the regional and urban relationships in its future development. For this reason, we started the characterization of the metropolitan urbanization of the area as a whole, through a cartographic analysis of human settlements from three variables: population, surface area, and total density in the metropolitan area, from which the main groups of territorial density were established. First, the total land area of the territory, which is ranked third by size nationwide. The municipal urbanized area accounts for only $3.63 \%$ of the total area of the municipality. This area includes all urban activities that can be observed on the land cover dedicated to urban uses, including uncultivated areas with signs of change in land use. The approximate area of agricultural use accounts for $16 \%$ of the total municipal area. The remaining $96.37 \%$ is conformed by a cover of natural ground with or without vegetation and flooded areas without current use. The urbanized area is composed of 3,491 polygons identified for urban use, 1,830 of them representing a total area of $14,147.98$ ha devoted to different productive activities and with no resident population. The rest of the identified areas, 1,661 locations that match the 2010 population and housing census, represent a total area of $36,413.39$ ha, containing a total population of 977,880 people.

The predominant climate in the municipality is the BW (h')hw(x') Very dry, warm, that occurs in an area of $389,260.96$ ha representing $27.93 \%$ of the municipal area; followed by the weather type Whw(x') Very dry, semi-warm, which occupies an area of $263,579.00$ ha and represents $18.91 \%$ of the municipal area. Thirdly, the climate BShs(x') Very dry, semi-warm, which occupies an area of $224,193.57$ ha representing $16.09 \%$, altogether constituting $64.93 \%$ of its total territory. Because of its low annual precipitation, the Mexicali climate is a warm desert climate, according to the criteria of the Koppen climate classification. The temperature is rarely less than $3^{\circ} \mathrm{C}\left(37^{\circ} \mathrm{F}\right)$ or above $45^{\circ} \mathrm{C}\left(113^{\circ} \mathrm{F}\right)$. The extreme minimum temperature in record is $-8^{\circ} \mathrm{C}$ (December 15,1972 ), and the maximum is $52^{\circ} \mathrm{C}$ (July 28,1995 ). Summer is extremely hot, with daytime temperatures exceeding $35^{\circ} \mathrm{C}$ almost every day of the season, reaching temperature values up to $46^{\circ} \mathrm{C}$ and heat index over $60^{\circ} \mathrm{C}$ every year. Nights are warm and occasionally hot, reaching over $30^{\circ} \mathrm{C}$. The winter is mild and seldom frosts. Nighttime temperatures rarely drop below $3^{\circ} \mathrm{C}$, while in daytime rarely exceed $25^{\circ} \mathrm{C}$ [9].

The extreme climate characteristics in the Metropolitan Area recorded climate changes worldwide. In the specific case of Mexicali [11], they found that the current summer is hotter and more extense than it was twenty years ago, and has $2 \frac{1}{2}$ times more heat waves than in the 1971-1980 decade; the variables that characterize heat waves have an upward trend and the scenarios for the periods 2010-2039, 2040-2069, and 2070-2099, show that heat waves will increase 2.7, 4.6 and 6.9 times respectively, compared with the baseline scenario. The modernization of the settlements in the territory of the Metropolitan Area led the until recently native or agricultural land use sites to an increase in concrete slabs. The materials that are widespread in urbanization (asphalt, concrete, brick, glass, etc.) and present in the environment since the mid-1980s in urban concentrations, have resulted in the development of urban heat islands in Mexicali [12], which confirms that the process of urban development has been increasing its temperature values in the last decades. 
Mexico has no official historical statistics of the intensity of car use in the metropolitan areas of the country. Recently, however, an analysis of motorization trends and its impact on the evolution of metropolitan areas in Mexico was conducted. In the case of the metropolitan areas of Tijuana and Mexicali, the 1990-2010 period of kilometers-vehicle traveled KVR [7] were located. Both have access to import cars from the United States across the border in northern Mexico. However, Mexicali in particular ranked first on vehicles per capita at a municipal level in Mexico, 2000. The economic dynamics of Mexicali and the conditions of its natural environment increased the volume of route kilometers that equate it with the largest urban centers of the country. It is important to highlight that Mexicali, a city with low population density, has a KVR by car as high as Mexico City or Guadalajara [13]. It is clear that the aspects related to the characteristics of the natural environment in terms of soil, climate and mobility with which distributed humans move territorially, lead one to identify the importance that these variables have been acquiring in the urbanization process of the current metropolitan area studied.

\subsection{Proposed zoning}

From the analyzes performed on the Mexicali Grand Vision Project, a new zoning of land use planning was proposed, which considers the distribution of the population and the functional aspects of its management. Four main geographical zones were detected within the municipal territory: the Urban zone, the Valley, the Deserts, and the Coast. The Urban zone is concentrated in the municipal capital that is Mexicali and its conurbation with the delegations of González Ortega, Cerro Prieto and Progreso. In the Valley zone, the main locations are: Ciudad Morelos, Guadalupe Victoria and Estación Coahuila. In the Coastal zone, the port of San Felipe is located as its main town. The Deserts zone has almost no population and urban areas, and in it is located Laguna Salada and lots of mountains that enclose it. Cartographically, the municipality of Mexicali was divided into six regions, which are the ones we use in this work of zonification, and has 84 sub-regions that have available information. Region 1 includes the urban area of Mexicali; Region 2 includes the ejidos Nuevo León, Michoacán de Ocampo, Sinaloa and Hechicera; Region 3 includes the colonias Benito Juárez, Paredones, ejido Hermosillo, Ciudad Morelos and the town of Algodones, among others; Region 4 includes the Delta, ejido Guadalupe Victoria, Venustiano Carranza, and Estación Coahuila, among others; Region 5 comprises the town La Ventana, Rancho de Dios and sand springs, among others; and Region 6 comprises the whole area of San Felipe (Figure 1).

\subsection{Regional characterization}

Regional urbanization is a process marked by its demographic evolution and housing distribution in the metropolitan area and in each major locality of the six regions. Regionally, the population growth in the period 1990-2010 recorded its highest growth in the period 1990-1995, which was 2.94, the highest of the fouryear periods of information used. In this period, the population dynamics was 

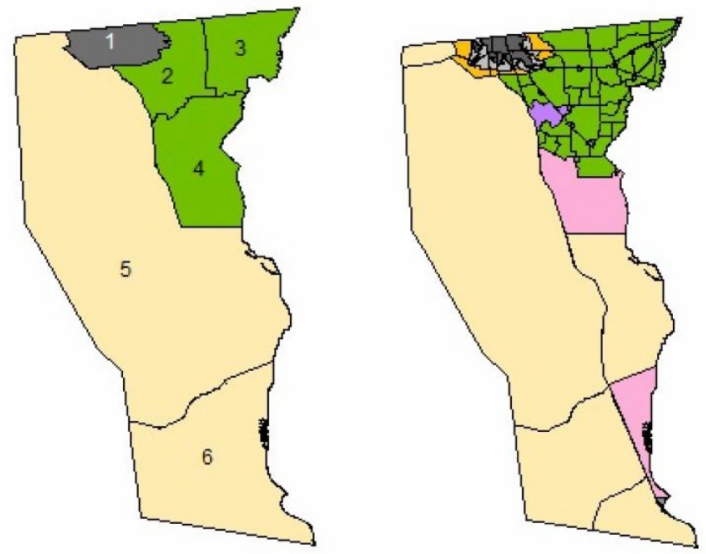

Figure 1: Regions and subregions of the metropolitan area of Mexicali. Source: Social Sciences Research Institute, UABC, 2011.

marked by two global economic crisis and in both countries of this border, which impacted the Mexicali metropolitan area. During this period, growth was marked by the reduction of employment for Mexicali residents in the United States and the reduction of employment and migrant population growth rates at a metropolitan level. These changes gave a total population growth rate of the metropolitan area of 1.82 in 2005-2010. Changes in demographic dynamics in the six regions over the period led to changes in the regional distribution of population and housing. Two regions experienced changes in increased housing during this period: firstly, the increases in population and housing were important in Region 6, which boosted tourist housing development during 1990-2000 in San Felipe for the US retirees market; secondly, Region 1 held a continuous growth, which was higher between 2000-2005 and resulted in Mexicali reaching the first place on housing nationwide in 2004, driven by mortgages [14], which promoted the expansion of housing in the area. In the case of the Valley regions, Region 2 experienced a growth in 1990-2000 to support the generation of energy. The three regions (2, 3 and 4$)$ experienced a decrease and a reduced increase in population during the 2000-2010 period.

In the period under review, the localities that experienced significant changes were: Region 1, which registered the continuous expansion of its urban concentration, integrating into its urbanization three geographically continuous localities; Region 6, which increased population and housing in the expansion of the urban concentration in San Felipe. In a sense, the US national housing policy and the retiree market marked the expansion in both urban concentrations. The behavior of the Mexicali Valley is distinguished from the previous ones because it experienced a process of stability in the population and housing proportions of the three regions that comprise it (2,3 and 4), highlighting the differences between Regions 2 and 4, which maintained their population and housing proportions during the period, and Region 3 that maintained its population and housing proportion during the 1990-2000 period and declined in the following. Of these 
behaviors, we attribute the high proportion of vehicles in the municipality to be a key instrument in the process of concentration and expansion because of the extreme conditions of the natural environment.

Environmentally, the Mexicali metropolitan area sits in the Physiographic Subprovince of the Lower Delta of the Colorado, of the Physiographic Province of the Sonoran Desert, and has a predominantly very dry, warm and semi-warm climate. Its environmental problems are referred to five main issues: solid waste, air pollution, water quality, green areas and environmental culture, although some issues are accentuated in some geographical areas [15].

In the Valley Zone, one of the main problems is the issue of solid waste, because although there are authorized landfills, many clandestine garbage handlers. Another problem is air pollution due to agricultural, waste and brick burning and agricultural spraying. There are also water quality problems associated with gastrointestinal and skin diseases. The Deserts Zone contributes mainly with dust pollution to other areas due to prevailing winds during the changing seasons, as well as sand and stone extraction without control. In the Coast Zone, the main problems are associated both with the quality of water, due to the overexploitation of aquifers and marine pollution due to discharges of untreated sewage, solid waste and oil spills, and with the affectation of native flora and fauna, derived from mining, agriculture and tourism. In the Urban Zone, one of the main problems is the lack of public green areas $\left(2.1 \mathrm{~m}^{2}\right.$ per inhabitant $)$ and the low maintenance of existing green areas. One of the common problems in all areas is the lack of an environmental culture regarding saving and reusing water, a lack of practical recycling of solid waste, saving energy and reducing greenhouse gas emissions. Recently, according to the Drought Monitor in Mexico, it was determined that in March 2015, Baja California was the only state in the country which saw extreme drought, reaching $23.8 \%$ of the state, and severe drought, reaching $30.4 \%$, part of this corresponding to Mexicali metropolitan area [16].

\subsection{Economic characterization}

It is important to note that originally agriculture gave life to the present territory of Mexicali metropolitan area, and gradually its own sectorial development shifted towards manufacturing activities and private and public services, which gradually strengthened the settlements adjacent to the US border, corresponding to Region 1 , where currently most of the metropolitan area establishments are concentrated.

In the case of agricultural activities, Region 1 has $67 \%$ of the establishments, Region 6 has 22\%, and Region 4 has $7 \%$. In the case of mining, power generation and construction, Region 4 concentrates $89 \%$, and Region 1 has $10 \%$. In manufacturing, Region 1 concentrates $87 \%$, while other regions range from $5 \%$ to less than $1 \%$. In trade and transportation, Region 1 concentrates $76 \%$, Region 4 has $13 \%$, Region 3 has $4 \%$, and it gradually reduces until Region 5 with less than $1 \%$. In mass media, financial and professional services, $90 \%$ is in Region 1 , while Region 4 has $4 \%$, and the rest is diluted. In health care, education and social assistance, $83 \%$ is concentrated in Region 1, 9\% in Region 3, and 4\% in Region 4, while the rest is diluted. In terms of entertainment services, accommodation and food, Region 1 accounts for $73 \%$, Region 4 has 16\%, and Region 6 has $6 \%$, while 
the reduction continues. In other services except government activities, Region 1 concentrated $84 \%, 6 \%$ in Region $4,0.5 \%$ in the 3 , continuing its reduction. On legislative, government and administration of justice activities, $81 \%$ was in Region $1,8 \%$ in Region 6, and the rest in the Mexicali Valley.

As a whole, Region 1 confirms the concentration of the highest percentage of economic establishments. The region that follows, Region 6, concentrates on San Felipe based on tourism, is another opportunity for future growth. Economically, it is noteworthy that the Mexicali Valley (comprising the towns of Guadalupe Victoria, Estación Delta, Venustiano Carranza, and Estación Coahuila ) as a whole constitutes the space most integrated to Region 1, the center of the metropolitan area, and its strength is constituted by the communications network and the number of vehicles that promote regional-urban integration of the diversified territory.

\subsection{Territorial suitability}

The calculation of the territorial suitability for urban use is based on the restrictions established in the diagnosis of the components of the physical and natural environment: slopes, geology and earthquakes, undoubted areas, and the environmental determinants of territorial vulnerability. Figure 2 shows the results of the interaction of the components, showing with darker color the tendency to lower territorial suitability for urban use.

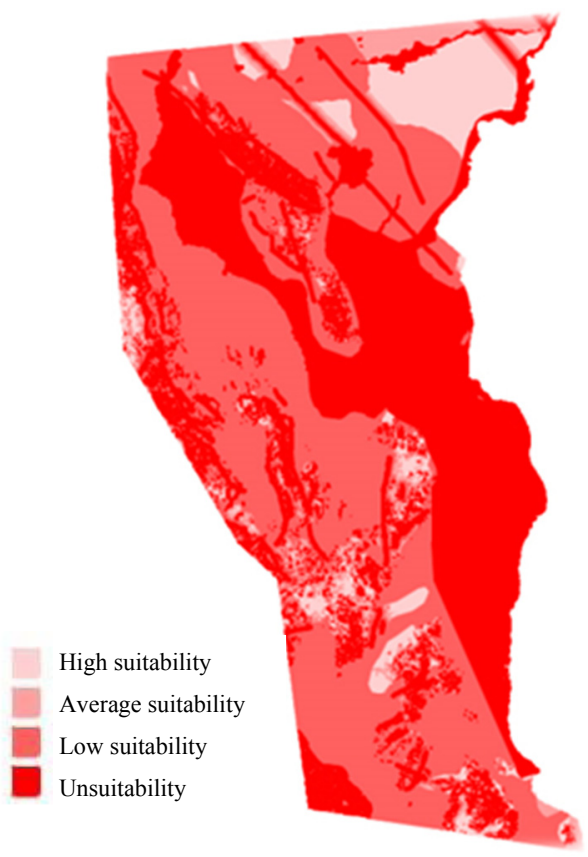

Figure 2: Soil suitability of the municipality of Mexicali. Source: Social Sciences Research Institute, UABC, 2013. 
The predominant surface has low suitability, comprising a surface of $666,832.97$ hectares and constituting $47.85 \%$; unsuitability covers an area of $501,932.39$ hectares and accounts for $36.02 \%$; surface with high suitability comprises $138,212.91$ hectares and amounts to $9.92 \%$. This data can be seen in Table 1.

Table 1: Soil suitability of the municipality of Mexicali. Source: Social Sciences Research Institute, UABC, 2013.

\begin{tabular}{cccccc}
\hline \multirow{2}{*}{ ID } & Description & Value & \multicolumn{2}{c}{ Surface } & Suitability \\
& & & Hectares & $\%$ & Index \\
\hline 0 & Unsuitability & 0 & $501,932.39$ & $36.02 \%$ & 0.00 \\
1 & Low Suitability & 1 & $666,832.97$ & $47.85 \%$ & 0.48 \\
2 & Average Suitability & 2 & $86,583.02$ & $6.21 \%$ & 0.12 \\
3 & High Suitability & 3 & $138,212.91$ & $9.92 \%$ & 0.30 \\
\hline & & & $1,393,561.30$ & $100.00 \%$ & 0.90 \\
\hline
\end{tabular}

Territorial suitability is used to determine the overall or gross maximum capacity to accommodate population in conditions of sustainability for urban use. The calculation results do not mean the population to inhabit it, but indicates the conditions of habitation that may be demanded from the territory. The specific local population depends on the urban character of the area, the demographic trends, economic activity and the availability of technology.

In the case of the municipality of Mexicali, there are environmental conditions that will reduce the gross soil suitability, mainly due to water conditions and land use for agricultural activities.

For this, existing settlements were verified in relation to the territorial suitability, calculating the gross population relocation needs, as they are in potential risk areas. A map that crossed territorial suitability variables with the polygons of settlements in the metropolitan area was elaborated, allowing to identify a total of 91,442 people settled in territorial areas classified as unsuitable, $9.76 \%$ of the total population of the municipality, housed in 25,386 households, of which 5,870 are unoccupied and 1,844 are of temporary use. These unsuitable areas inside urban areas occupy a total area of 9,488.71 has. The existing potential risk must be confirmed by more detailed studies or by establishing stricter safety standards in the construction of infrastructure and building.

\subsection{Scenarios}

From the work of participatory planning heightened within the proposed City of Great Vision we determined which were the problems and the challenges of the future development. These were agreed among groups of participatory planning and openly consulted to the population through Internet and surveys. The construction of each scenario was linked to the municipal development priorities selected for the first phase of public consultation. Thus allowing the identification 
of the strategic elements whose impact would generate an overall synergy for metropolitan development. There are three strategic elements that create a synergy for the overall development: The first one was Urban Growth, represented by the growth profile of urban areas. The second is Transports, which represents the mobility of people, goods and services and provides the functionality and urban efficiency, impacting with the elements of physical and environmental support. Finally, Socioeconomic Development, the third factor, represents the quality in the development of social context and economic welfare.

To generate a planning scenario that could describe the modeled predictions of development trends in the territory, a specialized computer program was used. Based on territorial statistics and diagnostic information generated and processed in the sustainable development model to construct spatial distribution alternatives for urban growth, taking as basis the physical, environmental and socioeconomic conditions of the territory. As a result we obtained scenarios to have an assessment of the consequences of current development trends of the ecological footprint of such process and the rate of urban sustainability over the time.

\section{Conclusions}

City-Region of Mexicali is a typical example of an ordered complexity where there is a great understanding of the components (demographic, economic and environmental) and how they relate.

The analysis of the City-Region of Mexicali is an opportunity for dynamic modeling, which raises trade relations within the immediate environment required by the urban metabolism of the system, showing the effects of the economic dynamics of export and maquila on the secondary and primary sectors, as well as migration flows not covered by local and municipal urban planning. The contribution is to identify trends and local development sectors that contribute to the sustainability of the urban development process observed in the city of Mexicali and its area of influence. From this possibility, the opportunities are promoted to ensure progress towards sustainable development: the reduction of social and regional inequalities, increasing housing supply, promoting public transport, reducing pollution, promoting the ecosystem and establishing a sustained government participation and cooperation of citizens to boost achievements and opportunities.

\section{References}

[1] Scott, A., Global City-Regions: Trends, Theory, Policy. Oxford University Press, 2002.

[2] Castells, M. \& Cardoso, G., The Network Society: From Knowledge to Policy. Washington, DC: Johns Hopkins Center for Transatlantic Relations, Washington, 2005.

[3] SEDESOL-CONAPO-SEGOB, Catalogo Sistema Urbano Nacional. México, 2012. 
[4] Diario Ofícial de la Federación, Reformas a la Ley Orgánica de la Administración Pública Federal para la creación de SEDATU 02-01-2013, 2013, México.

[5] Cabrero, E., et al., Competitividad de las ciudades en México: la nueva agenda urbana, México, D.F., Centro de Investigación y Docencia Económica- Secretaria de Economía, 2009.

[6] GREENPEACE, México ante el cambio climático, evidencias, impactos, vulnerabilidad y adaptación, México, 2010.

[7] Medina, S., Uso del Automóvil en México, Tendencias de Motorización, el uso del automóvil y sus impactos, ITDP-Embajada Británica en México, México, 2012.

[8] European Union, Regional Policy, Cities of tomorrow Challenges, visions, ways forward, 2011. http://ec.europa.eu/regional_policy/conferences/ citiesoftomorrow/index_en.cfm

[9] CEDEM, Plan Estratégico de la Zona Metropolitana de Mexicali 20152050, Mexicali, 2014.

[10] Ranfla, A., Rojas R., \& Bátiz J., Evolución económica global de México en la primera década del siglo XXI y su impacto en las zonas metropolitanas de los estados de Baja California y Chihuahua, 2014. http://www.rii.sei.ba.gov.br

[11] García-Cueto, O.R., Tejeda, A., \& Bojórquez, G., Urbanization effects upon the air temperature in Mexicali, B.C., Mexico. Atmósfera 22, pp. 349-365, 2009.

[12] García Cueto O.R., Santillán, N., Quintero, M., Ojeda, S. \& Velázquez, N., Extreme temperature scenarios in Mexicali, Mexico under climate change conditions, Atmósfera 26(4), pp. 509-520, 2013.

[13] CTS-Banco Mundial, Documento Base Sector Transporte para Estudio para la Disminución de Emisiones de Carbono (MEDEC). México: Centro de Transporte Sustentable- Banco Mundial, 2009.

[14] Instituto Mexicano para la Competitividad AC (IMCO), Índice de Competitividad Municipal en materia de Vivienda, 2011. http://imco.org.mx/wp-

[15] SPA-SIDUE-UABC, Programa para mejorar la calidad del aire en Mexicali 2011-2020, Gobierno de Baja California, Mexicali, 2011.

[16] Monitor Económico, Monitor Económico, Baja California, México, 2015. monitoreconomico.org/media/pdf/edicion.../2015/04/../15_abril_2015.p. 